\title{
A phase I study of pegylated liposomal doxorubicin and temsirolimus in patients with refractory solid malignancies
}

\author{
Andrea Wang-Gillam • Nilay Thakkar • A. Craig Lockhart $\cdot$ Kerry Williams $\cdot$ Maria Baggstrom • \\ Michael Naughton - Rama Suresh • Cynthia Ma - Benjamin Tan · Wooin Lee $\cdot$ Xuntian Jiang • Tibu Mwandoro • \\ Lauren Trull $\cdot$ Stefanie Belanger $\cdot$ Allison N. Creekmore $\cdot$ Feng Gao $\cdot$ Paula M. Fracasso $\cdot$ Joel Picus
}

Received: 2 April 2014 / Accepted: 14 May 2014 / Published online: 11 June 2014

(C) The Author(s) 2014. This article is published with open access at Springerlink.com

\begin{abstract}
This study aimed to determine the maximumtolerated dose and dose-limiting toxicities of pegylated liposomal doxorubicin (PLD) in combination with temsirolimus $(\mathrm{T})$ in patients with refractory solid tumors. Using a standard " $3+3$ " dose escalation design, 23 patients were enrolled in three dosing cohorts in this phase I study. The starting dose level was PLD at $30 \mathrm{mg} / \mathrm{m}^{2}$ every 4 weeks and $\mathrm{T}$ at $20 \mathrm{mg}$ weekly. Pharmacokinetics (PK) of doxorubicin were evaluated for patients in the expansion cohort. The most common treatment-related adverse events of all grades were mucositis/stomatitis (69.6\%), anorexia (52.2\%), thrombocytopenia $(52.2 \%)$, and fatigue $(47.8 \%)$. The recommended doses of this combination for phase II studies are $25 \mathrm{mg} / \mathrm{m}^{2}$ PLD and $25 \mathrm{mg}$ T. PK analyses suggested increased exposure of
\end{abstract}

Paula M. Fracasso and Joel Picus have contributed equally to this work.

Electronic supplementary material The online version of this article (doi:10.1007/s00280-014-2493-x) contains supplementary material, which is available to authorized users.

A. Wang-Gillam · A. C. Lockhart · M. Baggstrom

M. Naughton $\cdot$ R. Suresh $\cdot$ C. Ma $\cdot$ B. Tan $\cdot$ J. Picus $(\bowtie)$

Department of Medicine, Siteman Cancer Center, Washington

University School of Medicine, 660 South Euclid Ave., Campus

Box 8056, St. Louis, MO 63110, USA

e-mail: jpicus@dom.wustl.edu

N. Thakkar $\cdot$ W. Lee

Department of Pharmaceutical Sciences, College of Pharmacy,

University of Kentucky, Lexington, KY, USA

K. Williams

Banner Health Oncology Services, Northern Colorado, CO, USA

X. Jiang

Diabetic and Cardiovascular Disease Center, Washington

University School of Medicine, St. Louis, MO, USA doxorubicin in this combination regimen compared to doxorubicin administered as a single agent, possibly due to PK drug interactions. Out of 18 patients evaluable for a treatment response, two had partial responses (PR) (breast cancer and hepatocellular carcinoma) and six had stable disease (SD). Two patients remained on treatment for more than 1 year. The combination of PLD and T is tolerable, and the treatment resulted in clinical benefit. The combination regimen should be further explored in appropriate tumor types.

Keywords Pegylated liposomal doxorubicin .

Temsirolimus $\cdot$ Phase I study $\cdot$ Refractory malignancies

\section{Introduction}

The mammalian target of rapamycin (mTOR) acts downstream of the phosphatidyl-inositol 3 kinase (PI3K)/Akt pathway and plays a key role in the signaling of malignant cell proliferation, differentiation, migration, and survival

T. Mwandoro $\cdot$ L. Trull $\cdot$ S. Belanger $\cdot$ A. N. Creekmore Siteman Cancer Center, Washington University School of Medicine, St. Louis, MO, USA

F. Gao

Division of Biostatistics, Washington University School

of Medicine, St. Louis, MO, USA

P. M. Fracasso

Department of Medicine and the UVA Cancer Center, University of Virginia, Charlottesville, VA, USA 
[1]. Given that an overactive PI3K pathway is frequently implicated in the development and progression of a variety of malignancies, therapeutic targeting of crucial mediators along the PI3K signaling axis, such as mTOR, is an attractive strategy for cancer therapy.

Temsirolimus (T) (CCI-779, Torise $\mathrm{l}^{\circledR}$ Pfizer Inc.) is a soluble ester analog of sirolimus and exerts its antitumor effect by selectively inhibiting mTOR. Temsirolimus received approval from the Food and Drug Administration (FDA) for treating patients with advanced renal cell carcinoma, based on a pivotal Phase 3 study demonstrating that patients receiving $\mathrm{T}$ had superior median overall survival when compared to those receiving interferon alpha alone or a combination of the two therapies $(10.9,7.3$, and 8.4 months, respectively, $p=0.008$ ) [2]. In addition, fewer patients in the $\mathrm{T}$ group experienced serious adverse events than the other two groups [2]. A second mTOR inhibitor everolimus (RAD-001, Afinitor ${ }^{\circledR}$ Norvartis Pharmaceuticals Co.) has also been approved for advanced renal cell carcinoma after sunitinib or sorafenib treatment failure and for progressive neuroendocrine tumors of pancreatic origin. Therefore, mTOR inhibition is a proven antitumor strategy and is being evaluated in clinical trials for other cancer indications.

Doxorubicin is a cytotoxic anthracycline antibiotic isolated from Streptomyces peucetius var. caesius, and exerts its antitumor effect via inhibition of topoisomerase II [3]. In comparison with conventional or liposomal doxorubicin formulations, the pegylated liposomal doxorubicin (PLD) has extended blood circulation time, improved tumor localization, and better tolerance than conventional formulations [4]. Since its FDA approval, PLD is prescribed for refractory metastatic ovarian cancer and AIDS-related Kaposi Sarcoma [5, 6].

Several reports have indicated that mTOR inhibition may enhance the antitumor effects of cytotoxic agents in an additive or synergistic manner when tested in vitro and in vivo models of multiple types of human cancers [7, 8]. In particular, one preclinical study suggested that mTOR inhibition can reverse doxorubicin resistance conferred by PTEN mutation/Akt activation [9].

Based on the evidence suggesting potential synergy between mTOR inhibition and doxorubicin, we conducted a phase I clinical study evaluating the combination of PLD and $\mathrm{T}$ in patients with refractory solid malignancies. Here, we report the results on the safety, tolerability, pharmacokinetics (PK), and efficacy of this combination regimen.

\section{Methods}

Study design

This phase I study was an open-labeled, dose escalation study of PLD and T in patients with refractory tumors. The
Table 1 Dose escalation schema

\begin{tabular}{lll}
\hline $\begin{array}{l}\text { Dose } \\
\text { levels }\end{array}$ & $\begin{array}{l}\text { Pegylated liposomal doxorubicin } \\
\left(\mathrm{mg} / \mathrm{m}^{2}\right) \text { every 4 weeks }\end{array}$ & $\begin{array}{l}\text { Temsirolimus } \\
(\mathrm{mg}) \text { weekly }\end{array}$ \\
\hline 1 & 30 & 20 \\
$1 \mathrm{~A}$ & 25 & 20 \\
$2 \mathrm{~A}^{\#}$ & 25 & 25 \\
\hline
\end{tabular}

\# Includes an expansion cohort

starting dose level (cohort 1 ) for the study was $30 \mathrm{mg} / \mathrm{m}^{2}$ PLD every 4 weeks and $20 \mathrm{mg}$ T weekly (Table 1). A single treatment cycle was defined as 4 weeks, and dose-limiting toxicities (DLTs) were defined during the first cycle only. If none out of three patients in a cohort experienced DLT, then three patients proceeded to the next dose level. If two or more patients experienced DLT, then dose escalation was stopped. If one patient developed DLT, then three more patients entered the same dose level. The maximally tolerated dose (MTD) was defined as one dose level immediately below the dose level at which two patients of a cohort (of 2-6 patients) experienced DLT during the first cycle. Baseline imaging was performed within 28 days prior to starting the study and repeated after every two treatment cycles. Tumor response was assessed by the Response Evaluation Criteria in Solid Tumors (RECIST) 1.0 guidelines. All responses were confirmed by repeat imaging in 4 weeks. Toxicities were graded according to National Cancer institute Common Terminology Criteria for Adverse Events (NCI CTCAE), version 3.0. Hematological DLTs were defined as grade 4 neutropenia of $\geq 7$ days duration, febrile neutropenia of any duration with temperature above $38.5^{\circ} \mathrm{C}$, grade 4 anemia, or grade 4 thrombocytopenia which required transfusion therapy on more than two occasions in 7 days. Non-hematological DLTs were defined as Grade 3 or 4 toxicity with the specific exceptions of nausea, vomiting, or anorexia. Grade 3 triglycerides were only considered a DLT after the administration of appropriate lipid-lowering agents. A delay of treatment for $\geq 14$ days (consecutive or cumulative) prior to beginning cycle 2 was considered a DLT.

\section{Patient population}

Patients were eligible to participate if they had a histological or cytological diagnosis of a malignant solid tumor that had progressed on standard therapies. Eligibility criteria included the following: life expectancy of at least 8 weeks; Eastern Cooperative Oncology Group (ECOG) performance status (PS) $\leq 2$; age $\geq 18$ years; measurable or evaluable disease as defined by RECIST; adequate bone marrow function [absolute neutrophil count (ANC) $\geq 1,500 / \mathrm{mm}^{3}$, hemoglobin $\geq 9 \mathrm{~g} / \mathrm{dL}$, and platelet count $\left.\geq 100,000 / \mathrm{mm}^{3}\right]$, 
adequate renal function (serum creatinine $\leq 2.0 \mathrm{mg} / \mathrm{dL}$ or creatinine clearance $\geq 60 \mathrm{ml} / \mathrm{min} / 1.73^{2}$ ); adequate hepatic function [aspartate aminotransferase (AST), alanine aminotransferase (ALT) level, alkaline phosphatase $\leq 2.5 \times$ institutional upper limit of normal (ULN), and total bilirubin level $\leq 1.5 \times \mathrm{ULN}$ ]; fasting cholesterol level $\leq 350 \mathrm{mg} / \mathrm{dL}$; fasting triglyceride $\leq 400 \mathrm{mg} / \mathrm{dL}$; albumin $<3 \mathrm{mg} / \mathrm{dL}$; and no active central nervous system (CNS) metastases, and normal left ventricular ejection fraction (LVEF $\geq 50 \%$ ) by multigated acquisition scan (MUGA). Patients may not have had chemotherapy or radiotherapy within 4 weeks of starting the protocol treatment. Patients must have provided signed and dated informed consent forms approved by the Washington University Human Research Protection Office (HRPO). All patients who received at least one treatment were included in the safety analysis. The study was conducted under the auspices of the Siteman Cancer Center Quality Assurance and Safety Monitoring Committee.

\section{Treatment administration and dose escalation procedure}

Patients received PLD intravenously once every 4 weeks and $\mathrm{T}$ by intravenous infusion weekly. No treatment cycle was started until ANC $\geq 1,500 / \mathrm{mm}^{3}$, the platelets count $\geq 100,000 / \mathrm{mm}^{3}$, hemoglobin $\geq 9.0 \mathrm{~g} / \mathrm{dL}$, and all other treatment-related toxicities were grade $\leq 1$. If, after the appropriate dose reductions, a treatment-related toxicity required a delay of $\geq 14$ days before starting subsequent cycles, the patient was taken off study. If any grade $\geq 2$ neutropenia or thrombocytopenia occurred at the start of a cycle, administration of both PLD and T was delayed (no more than 14 days) until the toxicity resolved to grade 1 or less. For patients experiencing toxicities, in subsequent cycles, PLD was given at a lower dose level while $\mathrm{T}$ could be resumed at the prior dose level or a reduced dose level at the discretion of the treating physician. For any occurrences of neutropenic fever, administration of either both drugs (at the start of a cycle) or $\mathrm{T}$ (during a cycle) was delayed until it resolved to grade $\leq 1$ and then both drugs were reduced by one dose level. Once the dose was reduced for a subject, all subsequent cycles for PLD were administered at the reduced dose.

If grade $\geq 2$ stomatitis/mucositis persisted at the start of a cycle, administration of both drugs was delayed until the toxicity resolved to grade $\leq 1$, and the drug deemed responsible for the stomatitis/mucositis was reduced by one dose level in the current and subsequent cycles. If neither drug was identified as being responsible for the adverse events, then both drugs were reduced by one dose level. If grade $\geq 2$ stomatitis/mucositis occurred during the weeks $2-4$ of a cycle, $T$ was omitted from the regimen until the stomatitis/mucositis resolved to grade $\leq 1$; then, the drug deemed responsible for the adverse event was reduced in the current and subsequent cycles.

Pharmacokinetic (PK) analyses

The PK of doxorubicin were assessed by analyzing the concentrations of doxorubicin in plasma samples collected at 0 (pre-dose), 0.5, 1.5, and $5 \mathrm{~h}$ after the start of drug infusion and approximately 48,96 , and $168 \mathrm{~h}$ post-infusion. Plasma concentrations of doxorubicin were analyzed using a liquid chromatography mass spectrometry analytical method (detailed description of bioanalytical methods provided in supplementary materials). The PK parameters were estimated using non-compartmental methods. The area under the concentration-time curve from time 0 to the last sampling point $\left(\mathrm{AUC}_{\text {last }}\right)$ was calculated using the linear trapezoidal method. The remaining area under the curve from the last time point to infinity was calculated using the equation $\mathrm{AUC}_{\text {last- }-\infty}=C_{\text {last }} / k_{\mathrm{el}}$, where $C_{\text {last }}$ is the last-measured plasma concentration and $k_{\mathrm{el}}$ is the slope of the concentration versus time plot during the log-linear terminal phase. Total clearance $(\mathrm{CL})$ and elimination half-life $\left(t_{1 / 2}\right)$ were calculated as follows: $\mathrm{CL}=$ dose/AUC, $t_{1 / 2}=0.693 / k_{\mathrm{el}}$.

\section{Statistical methods}

The primary outcome of this study was assessment of toxicity. The results are summarized by simple descriptive summary statistics. The PK variables for doxorubicin obtained using non-compartmental methods are summarized using mean \pm standard deviations.

\section{Results}

Patient characteristics

From April 2008 to June 2011, a total of 23 patients were enrolled and treated with PLD and T. Demographic information for the study participants is shown in Table 2 . The median age of patients was 60 years (range 34-80 years). The majority of the patients were Caucasian (21 of 23), and $14(60.9 \%)$ patients were male. The distribution of ECOG PS of 0 and 1 was 21.7 and $65.2 \%$, respectively. Twentyone $(91.3 \%)$ patients had received at least one line of prior chemotherapy for their cancer. The most common cancer diagnoses were colorectal cancer $(30.4 \%)$ and breast can$\operatorname{cer}(17.4 \%)$.

\section{Safety and toxicity}

The treatment toxicities experienced during the first cycle of treatment are summarized in Table 3. Six patients were 
Table 2 Baseline clinical and demographic characteristics of enrolled patients

\begin{tabular}{|c|c|c|}
\hline \multirow[t]{2}{*}{ Characteristic } & \multicolumn{2}{|c|}{ Patients $(n=23)$} \\
\hline & No. & $\%$ \\
\hline \multicolumn{3}{|l|}{ Gender } \\
\hline Male & 14 & 60.9 \\
\hline Female & 9 & 39.1 \\
\hline \multicolumn{3}{|l|}{ Age (years) } \\
\hline Median & 60 & \\
\hline Range & $34-80$ & \\
\hline \multicolumn{3}{|l|}{ Ethnicity } \\
\hline Caucasian & 21 & 91.3 \\
\hline African Americans & 2 & 8.7 \\
\hline \multicolumn{3}{|l|}{ ECOG performance status } \\
\hline 0 & 5 & 21.7 \\
\hline 1 & 15 & 65.2 \\
\hline 2 & 3 & 13.1 \\
\hline $\begin{array}{l}\text { Number of previous chemotherapy } \\
\text { regimens (median, range) }\end{array}$ & $4(0-11)$ & \\
\hline \multicolumn{3}{|l|}{ Previous radiation } \\
\hline No & 7 & 30.4 \\
\hline Yes & 16 & 69.6 \\
\hline \multicolumn{3}{|l|}{ Primary tumor type } \\
\hline Colorectal & 7 & 30.4 \\
\hline Breast & 4 & 17.4 \\
\hline Non-small cell lung & 3 & 13.1 \\
\hline Hepatocellular & 2 & 8.7 \\
\hline Others ${ }^{\#}$ & 7 & 30.4 \\
\hline
\end{tabular}

\# One patient each for prostate, gallbladder, esophageal, parotid gland, adrenal gland, squamous cell carcinoma of the skin, and malignant solitary fibrous tumor

treated in dose level 1 cohort (PLD $30 \mathrm{mg} / \mathrm{m}^{2}$ and T $20 \mathrm{mg}$ ); however, one patient never received treatment as she was determined to be ineligible after enrollment. Of the remaining five patients, no DLTs were observed (Table 4). Interim analysis was performed on this cohort. Although there were no DLTs at this dose level, the majority of patients were unable to complete two full cycles of treatment for evaluation of response, so the decision was made to reduce the starting dose level of PLD from $30-25 \mathrm{mg} / \mathrm{m}^{2}$.

Six patients were enrolled in the dose level $1 \mathrm{~A}$ cohort (PLD $25 \mathrm{mg} / \mathrm{m}^{2}$ and $\mathrm{T} 20 \mathrm{mg}$ ), and one patient experienced the following DLTs [elevated AST (SGOT), hyperglycemia, and dyspnea]. Dose escalation proceeded as per the study protocol to dose level 2A. Six patients were enrolled in cohort 2A (PLD $25 \mathrm{mg} / \mathrm{m}^{2}$ and T $25 \mathrm{mg}$ ). One patient did not receive any treatment. Among five treated patients in this cohort, none experienced DLTs; therefore, this dose level was expanded. Seven patients were enrolled in the expansion cohort, for a total of 12 patients treated at this dose level. Adverse events in each cohort are summarized in Table 3. The common treatment-related adverse events during cycle 1 were: mucositis/stomatitis $(16 / 23,69.6 \%)$, anorexia $(12 / 23,52.2 \%)$, platelets $(12 / 23,52.2 \%)$, and fatigue $(11 / 23,47.8 \%)$.

The reasons patients discontinued treatment in this study are summarized in Table 4. Fifteen patients $(65.2 \%)$ were taken off the study due to disease progression. Two patients were removed from the study based on the investigator/ patient's decisions. One patient in cohort 2A developed recurrent mucositis, and the subject was taken off the study because no further dose reduction for $\mathrm{T}$ was permissible.

\section{Pharmacokinetics}

PK analyses of doxorubicin were performed following the intravenous infusion of PLD at $25 \mathrm{mg} / \mathrm{m}^{2}$ on day 1 of cycle 2 in 6 out of 7 patients in the expansion cohort of 2A (Fig. 1; Table 5). One patient in the expansion cohort did not have blood collected for PK on day 1 of cycle 2 due to disease progression. The plasma concentrations of doxorubicin were well above the lower quantitation limit at all time points. Although the PK blood sampling schedule was limited, it was possible to obtain reliable estimates of the terminal $t_{1 / 2}$ from the regression analyses of the terminal log-linear decline (Fig. 1). Since the PK analyses were performed only on day 1 of cycle 2 , it was not possible to assess the potential impact of the co-administered $\mathrm{T}$ on the PK of doxorubicin within our study. Thus, the results were compared to those available from the literature; in a previous study with the same $25 \mathrm{mg} / \mathrm{m}^{2}$ dose of PLD, the average terminal $t_{1 / 2}, \mathrm{AUC}_{0-\infty}$, and CL values were $45.2 \mathrm{~h}$ (range 20.8-59.1), $609 \mu \mathrm{g}_{*} \mathrm{~h} / \mathrm{ml}$ (range 227-887), and $80 \mathrm{ml} / \mathrm{h}$ (range 50-210), respectively [10]. The comparison of PK parameters obtained from our current study and similar studies in the literature is summarized in Table 5 $[10,11]$. The results suggest that the systemic exposure of doxorubicin is much greater in patients receiving the combination therapy than in patients receiving PLD alone.

\section{Efficacy}

Of 23 patients enrolled in the study, 18 were determined to be evaluable for treatment response because they had completed at least one cycle of treatment and one post-baseline imaging assessment. Five patients were not evaluable for treatment response due to the following reasons; no postbaseline imaging study $(n=2)$, consent withdrawal for grade 2 stomatitis $(n=1)$, discontinuation due to recurrent grade 2 stomatitis $(n=1)$, and discontinuation due to no further dose reduction available for $\operatorname{PLD}(n=1)$. Figure 2 shows a waterfall plot of the treatment effect. Two $(11.1 \%)$ patients showed PR and six (33.3\%) patients displayed SD 
Table 3 Summary of common drug-related adverse events occurring during the first cycle of treatment
\# Dose-limiting toxicity

Table 4 Summary of reasons that subjects discontinued study participation

\# Dose-limiting toxicity

\begin{tabular}{|c|c|c|c|c|c|c|c|c|c|c|c|c|}
\hline \multirow[t]{4}{*}{ Grade of adverse event } & \multicolumn{12}{|c|}{ Dose level } \\
\hline & \multicolumn{4}{|c|}{$1(n=5)$} & \multicolumn{4}{|c|}{$1 \mathrm{~A}(n=6)$} & \multicolumn{4}{|c|}{$2 \mathrm{~A}(n=12)$} \\
\hline & \multicolumn{4}{|c|}{ Grade } & \multicolumn{4}{|c|}{ Grade } & \multicolumn{4}{|c|}{ Grade } \\
\hline & 1 & 2 & 3 & 4 & 1 & 2 & 3 & 4 & 1 & 2 & 3 & 4 \\
\hline Mucositis/stomatitis & & 3 & & & 1 & 2 & & & 7 & 3 & & \\
\hline Anorexia & 2 & 2 & & & 2 & 1 & & & 2 & 3 & & \\
\hline Platelets & 1 & & & & 4 & & & & 6 & & 1 & \\
\hline Fatigue & 1 & & & & & 2 & & & 3 & 4 & 1 & \\
\hline Leukocytes & & 1 & & & & 1 & & & 3 & 4 & & \\
\hline Nausea & 1 & 2 & & & 1 & & & & 4 & 1 & & \\
\hline Hemoglobin & 2 & & & & 1 & 1 & & & 3 & 1 & & \\
\hline Lymphocyte & & 1 & & & 1 & 2 & & & 1 & 1 & 3 & \\
\hline Albumin & 2 & & & & 2 & & & & 2 & & & \\
\hline AST (SGOT) & & & & & 1 & 1 & $1^{\#}$ & & 2 & 1 & & \\
\hline Pain: headache & 2 & & & & 2 & 1 & & & 1 & & & \\
\hline ALT (SGTP) & & & & & 2 & 2 & & & 1 & & & \\
\hline Dyspnea & & & & & 1 & & & $1^{\#}$ & 1 & 1 & 1 & \\
\hline Heartburn/dyspepsia & 1 & 1 & & & 1 & & & & 2 & & & \\
\hline Rash/desquamation & 2 & 1 & & & 1 & & & & & 1 & & \\
\hline Glucose (serum) & & & & & & & $2^{\#}$ & & & 1 & 1 & \\
\hline Neutrophils & & & 1 & & & & & & 1 & 2 & & \\
\hline Triglyceride (serum) & & & & & 1 & & & & 1 & 2 & & \\
\hline Pruritus & 3 & 1 & & & & & & & & & & \\
\hline
\end{tabular}

\begin{tabular}{lllll}
\hline Reasons for treatment cessation & $1(n=5)$ & $1 \mathrm{~A}(n=6)$ & $2 \mathrm{~A}(n=12)$ & Total $(n=23)$ \\
\hline Disease progression & 1 & 5 & 9 & 15 \\
Investigator/patient decision & 1 & 0 & 1 & 2 \\
Adverse event & 1 & $1^{\#}$ & 0 & 2 \\
Intercurrent illness & 1 & 0 & 1 & 2 \\
No further dose reduction allowed on study & 1 & 0 & 1 & 2 \\
\hline
\end{tabular}

by RECIST. Several patients with less than $20 \%$ increase in the maximum changes from the baseline were deemed to have progressive disease due to the appearance of one or more new lesions. One patient with a PR (dose cohort 2A) was on treatment for 6 months, and she was taken off study because there was no further dose reduction of $\mathrm{T}$ allowed for her recurrent stomatitis. This patient had breast cancer, and she had received three lines of chemotherapy before starting on this trial. The second patient with a PR (dose cohort 1) had hepatocellular cancer (HCC), and she was treated for 15 months and then removed for disease progression.

Among the seven patients with SD, the tumor types included HCC ( $n=1)$, non-small cell lung cancer $(n=2)$, colorectal cancer $(n=2)$, squamous cell carcinoma of the skin $(n=1)$, and malignant solitary fibrous tumor $(n=1)$. The median treatment duration was 4 months (range
2-12 months). A patient with squamous cell carcinoma of the skin received a total of 12 cycles of treatment and had received 3 lines of chemotherapy prior to enrolling in the trial.

\section{Discussion}

In this phase I study, we assessed the safety and tolerability of the combination of PLD and T in patients with refractory solid tumors. Based on our study, PLD at $25 \mathrm{mg} / \mathrm{m}^{2}$ every 4 weeks and $\mathrm{T}$ at $25 \mathrm{mg}$ weekly appeared to be tolerable for patients with refractory solid tumors and is the recommended Phase II dose. The observed DLTs were elevated AST (SGOT), hyperglycemia, and dyspnea, and the most common adverse event of this combination drug regimen was mucositis/stomatitis, which was observed in $16(69.6 \%)$ patients but at grade $\leq 2$ (Table 3 ). 


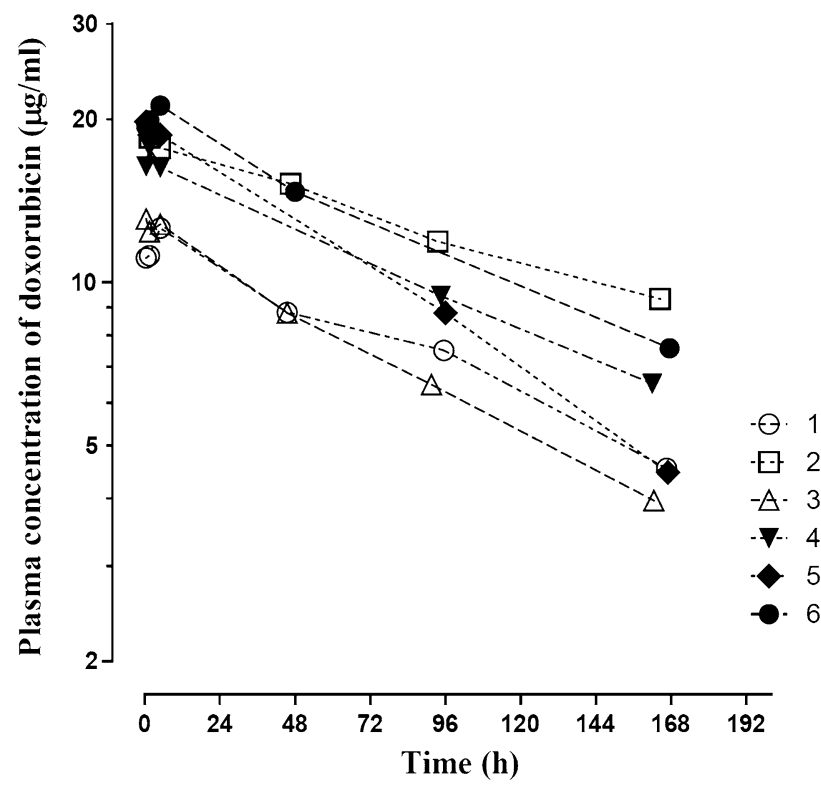

Fig. 1 Individual plasma concentration versus time profiles of doxorubicin following intravenous administration of PLD $\left(25 \mathrm{mg} / \mathrm{m}^{2}\right)$ on the day 1 of cycle 2 in six patients

Table 5 Pharmacokinetic (PK) parameters of doxorubicin in six patients after intravenous administration of PLD $\left(25 \mathrm{mg} / \mathrm{m}^{2}\right)$ on day 1 of cycle 2

\begin{tabular}{lcc}
\hline PK parameters & Median (ranges) & $\begin{array}{l}\text { Median (ranges) } \\
{[10,11]}\end{array}$ \\
\hline$t_{1 / 2}(\mathrm{~h})$ & $115(79-165)$ & $45.2(20.8-59.1)$ \\
$\mathrm{AUC}_{0-\infty}\left(\mu \mathrm{g}_{*} \mathrm{~h} / \mathrm{mL}\right)$ & $2,600(1,800-4,375)$ & $609(227-887)$ \\
$\mathrm{CL}(\mathrm{mL} / \mathrm{h})$ & $19(11-26)$ & $80(50-210)$ \\
\hline
\end{tabular}

These patients also received weekly $\mathrm{T}(25 \mathrm{mg})$. The PK parameters from a previous study in patients receiving the $25 \mathrm{mg} / \mathrm{m}^{2}$ dose of PLD alone are also provided [10,11]

$\mathrm{AUC}_{0-\infty}=$ Area under the concentration versus time curve; $t_{1 / 2}=$ Elimination half-life; $\mathrm{CL}=$ Total clearance

A recently reported study independently determined that PLD at $30 \mathrm{mg} / \mathrm{m}^{2}$ every 4 weeks and $\mathrm{T}$ at $20 \mathrm{mg} / \mathrm{m}^{2}$ weekly as the MTD in patients with refractory or recurrent bone and soft tissue sarcoma [12]. The study enrolled 15 adult and pediatric patients, and their median age was 39 (range 9-70), much younger than those who participated in our current study (median 60, range 34-80, Table 2). In our study, the starting dose level was $30 \mathrm{mg} / \mathrm{m}^{2}$ PLD every 4 weeks and $20 \mathrm{mg} \mathrm{T}$. However, the majority of patients who received this starting dose level could not complete two full cycles of treatment for a true evaluation of response, so PLD was reduced to $25 \mathrm{mg} / \mathrm{m}^{2}$ in the subsequent cohorts. Based on the recommended $\mathrm{T}$ single agent dose of $25 \mathrm{mg}$ weekly, we further explored the combination of PLD at $25 \mathrm{mg} / \mathrm{m}^{2}$ and $\mathrm{T}$ at $25 \mathrm{mg}$ weekly, which we determined to be the phase II dose for this combination regimen. Of note, our current study used the typical fixed $\mathrm{mg}$ dose of $\mathrm{T}$ approved by the FDA rather than $\mathrm{mg} / \mathrm{m}^{2}$ used in the recent sarcoma study which probably required dose adjustment for the pediatric population enrolled [12]. Therefore, we believe that the phase II dose for the combination regimen from our study (PLD at $25 \mathrm{mg} / \mathrm{m}^{2}$ every 4 weeks and $\mathrm{T}$ at $25 \mathrm{mg}$ weekly) may be more applicable to a general patient population with solid tumors.

The results from our PK analyses for doxorubicin also appear to be in line with the findings reported in the recent report in sarcoma patients [12]. Our results indicate that the weekly administration of $\mathrm{T}$ may have an impact on the PK profiles of doxorubicin when compared to the reported PK variables in the literature (Table 5). Our current study involved the PK assessment of doxorubicin only, due to the limited availability of blood samples from the enrolled patients. However, the recent report in sarcoma patients demonstrated that the concurrent administration of $\mathrm{T}$ and PLD resulted in increased systemic exposure (approximately twofold increase in AUC) of sirolimus, a major active metabolite of $\mathrm{T}$ [12]. These observed changes in the systemic exposure of doxorubicin and sirolimus are consistent with the previous reports that $\mathrm{T}$, sirolimus, and doxorubicin are substrates for CYP3A4 and also for P-glycoprotein $[13,14]$. Increased systemic exposure of doxorubicin and sirolimus when the two drugs were administered concurrently compared with single agent alone as well as some overlapping toxicities (e.g., mucositis) may have contributed to the adverse events observed in our study. Further investigations are warranted in order to probe the extent of the potential drug interactions for this combination regimen.

Emerging preclinical evidence suggests that mTOR inhibition can potentiate the antitumor efficacy of conventional cytotoxic agents in multiple tumor types in vivo and in vitro $[7,8]$. Moreover, mTOR inhibition can overcome acquired cancer resistance to drugs targeting topoisomersase II [9, 15]. These preclinical observations may be clinically relevant as we observed clinical benefit in $44.4 \%$ of patients; 6 stable diseases (SD, $33.3 \%$ ) and 2 partial responses (PR, $11.1 \%$ ) out of eighteen patients evaluable for treatment response. The duration of treatment for patients with SD was 4 months. Similarly, PLD and T have been combined with bevacizumab in another phase I study [16]. Out of 74 patients with advanced gynecologic and breast malignancies in that study, clinical benefit was achieved in $37.8 \%$ of patients; 1 (1.4\%) complete response (CR), 14 (18.9\%) $\mathrm{PR}$, and 13 (17.6 \%) SD. Moreover, when assessed in patients with PI3K pathway aberrations (PI3K mutation or PTEN loss), this combination regimen resulted in clinical benefits $(\mathrm{CR}+\mathrm{PR}+\mathrm{SD})$ in $52 \%$ of patients; $9(36 \%)$ $\mathrm{CR} / \mathrm{PR}$ and 4 (16\%) SD [16]. Our current study did not involve mutational analyses for PI3K pathway aberrations, 
Fig. 2 Waterfall plot of treatment response for 18 evaluable patients treated with PLD and T. Best tumor response (\%) assessed by the Response Evaluation Criteria in Solid Tumors (RECIST) is plotted for individual patients. Several patients with less than $20 \%$ increase in the maximum changes from the baseline were deemed to have progressive disease due to the appearance of one or more new lesions

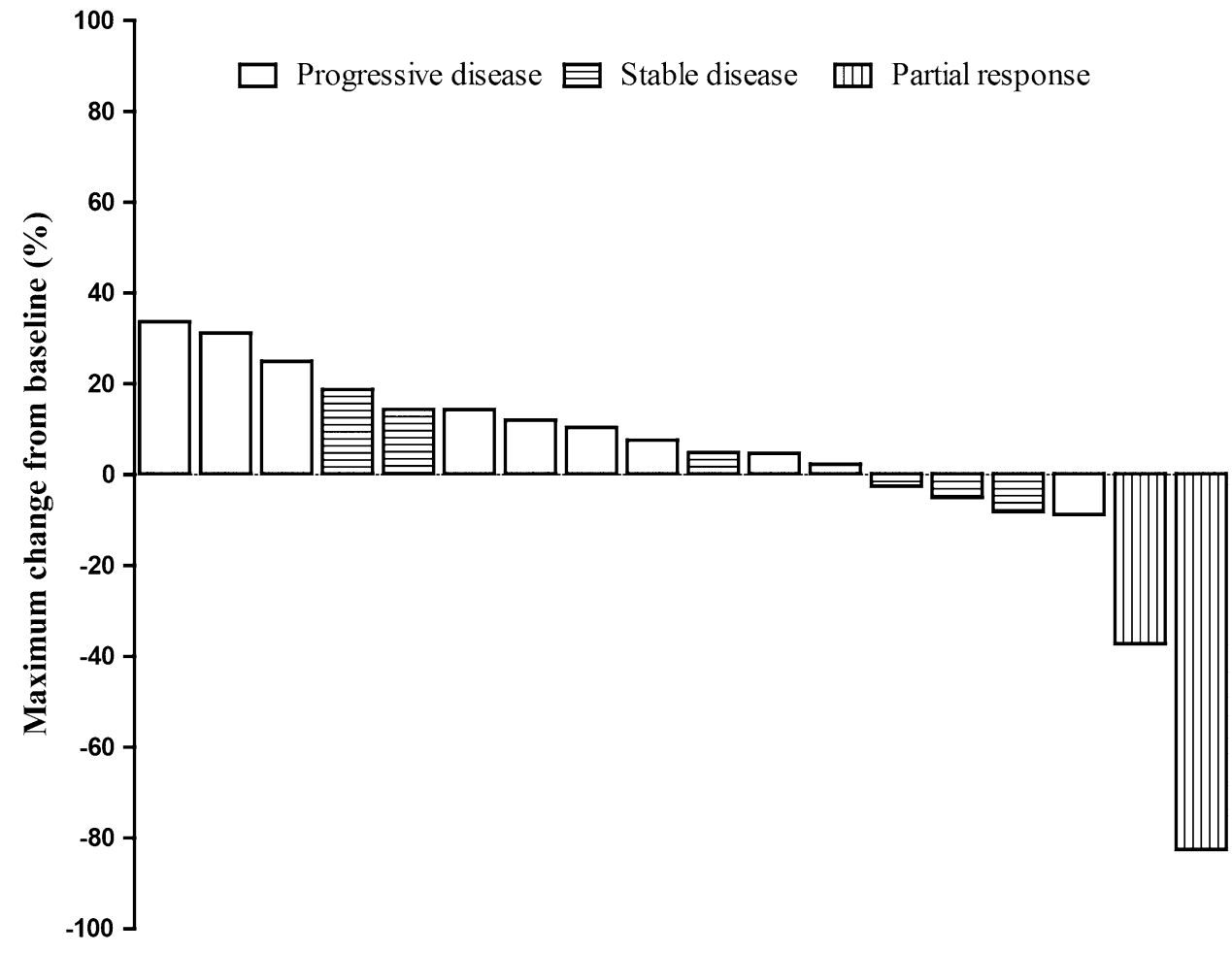

but a subsequent study of this regimen enriched with patients selected for these molecular/genetic markers may be warranted.

In summary, the results from our current study demonstrated that the combination of PLD and T is tolerable and can yield clinical benefit. The combination regimen should be further explored in a phase II trial in patients with appropriate tumor types (e.g., advanced HCC, a disease with very limited therapeutic options). The efficacy of the combination regimen and the PK interaction between the two drugs warrant further exploration.

Acknowledgments The authors would like to thank all the patients who participated in this study and also to acknowledge Pfizer for their support of this study.

Conflict of interest The authors declare that they have no conflict of interest.

Open Access This article is distributed under the terms of the Creative Commons Attribution License which permits any use, distribution, and reproduction in any medium, provided the original author(s) and the source are credited.

\section{References}

1. Janus A, Robak T, Smolewski P (2005) The mammalian target of the rapamycin (mTOR) kinase pathway: its role in tumourigenesis and targeted antitumour therapy. Cell Mol Biol Lett 10(3):479-498
2. Hudes G, Carducci M, Tomczak P, Dutcher J, Figlin R, Kapoor A, Staroslawska E, Sosman J, McDermott D, Bodrogi I, Kovacevic Z, Lesovoy V, Schmidt-Wolf IG, Barbarash O, Gokmen E, O'Toole T, Lustgarten S, Moore L, Motzer RJ, Global AT (2007) Temsirolimus, interferon alfa, or both for advanced renal-cell carcinoma. N Engl J Med 356(22):2271-2281. doi:10.1056/NEJ Moa066838

3. Arcamone F, Cassinelli G, Fantini G, Grein A, Orezzi P, Pol C, Spalla C (2000) Adriamycin, 14-hydroxydaunomycin, a new antitumor antibiotic from $S$. peucetius var. caesius. Reprinted from Biotechnology and Bioengineering, Vol. XI, Issue 6, Pages 11011110 (1969). Biotechnol Bioeng 67(6):704-713

4. Muggia FM (1997) Clinical efficacy and prospects for use of pegylated liposomal doxorubicin in the treatment of ovarian and breast cancers. Drugs 54(Suppl 4):22-29

5. Gordon AN, Fleagle JT, Guthrie D, Parkin DE, Gore ME, Lacave AJ (2001) Recurrent epithelial ovarian carcinoma: a randomized phase III study of pegylated liposomal doxorubicin versus topotecan. J Clin Oncol 19(14):3312-3322

6. Harrison M, Tomlinson D, Stewart S (1995) Liposomal-entrapped doxorubicin: an active agent in AIDS-related Kaposi's sarcoma. J Clin Oncol 13(4):914-920

7. Abrams SL, Steelman LS, Shelton JG, Wong EW, Chappell WH, Basecke J, Stivala F, Donia M, Nicoletti F, Libra M, Martelli AM, McCubrey JA (2010) The Raf/MEK/ERK pathway can govern drug resistance, apoptosis and sensitivity to targeted therapy. Cell Cycle 9(9):1781-1791

8. O'Reilly T, McSheehy PM, Wartmann M, Lassota P, Brandt R, Lane HA (2011) Evaluation of the mTOR inhibitor, everolimus, in combination with cytotoxic antitumor agents using human tumor models in vitro and in vivo. Anticancer Drugs 22(1):5878. doi:10.1097/CAD.0b013e3283400a20

9. Grunwald V, DeGraffenried L, Russel D, Friedrichs WE, Ray RB, Hidalgo M (2002) Inhibitors of mTOR reverse doxorubicin resistance conferred by PTEN status in prostate cancer cells. Cancer Res 62(21):6141-6145 
10. Gabizon A, Catane R, Uziely B, Kaufman B, Safra T, Cohen R, Martin F, Huang A, Barenholz Y (1994) Prolonged circulation time and enhanced accumulation in malignant exudates of doxorubicin encapsulated in polyethylene-glycol coated liposomes. Cancer Res 54(4):987-992

11. Gabizon A, Shmeeda H, Barenholz Y (2003) Pharmacokinetics of pegylated liposomal doxorubicin: review of animal and human studies. Clin Pharmacokinet 42(5):419-436

12. Thornton KA, Chen AR, Trucco MM, Shah P, Wilky BA, Gul N, Carrera-Haro MA, Ferreira MF, Shafique U, Powell JD, Meyer CF, Loeb DM (2013) A dose-finding study of temsirolimus and liposomal doxorubicin for patients with recurrent and refractory bone and soft tissue sarcoma. Int J Cancer 133(4):997-1005. doi:10.1002/ijc. 28083

13. Yacyshyn BR, Bowen-Yacyshyn MB, Pilarski LM (1996) Inhibition by rapamycin of P-glycoprotein 170-mediated export from normal lymphocytes. Scand J Immunol 43(4):449-455
14. Boni JP, Leister C, Burns J, Hug B (2008) Differential effects of ketoconazole on exposure to temsirolimus following intravenous infusion of temsirolimus. Br J Cancer 98(11):1797-1802. doi:10. 1038/sj.bjc.6604376

15. Gaur S, Chen L, Yang L, Wu X, Un F, Yen Y (2011) Inhibitors of mTOR overcome drug resistance from topoisomerase II inhibitors in solid tumors. Cancer Lett 311(1):20-28. doi:10.1016/j.canlet.2011.06.005

16. Moroney JW, Schlumbrecht MP, Helgason T, Coleman RL, Moulder S, Naing A, Bodurka DC, Janku F, Hong DS, Kurzrock R (2011) A phase I trial of liposomal doxorubicin, bevacizumab, and temsirolimus in patients with advanced gynecologic and breast malignancies. Clin Cancer Res 17(21):6840-6846. doi:10.1158/1078-0432.ccr-11-0666 